\title{
Efeito do óleo de eucalipto (Corymbia citriodora) no controle do carrapato bovino
}

\author{
Effect of eucalyptus oil (Corymbia citriodora) on the control of cattle ticks
}

\author{
Clair Jorge Olivo ${ }^{\mathrm{I}}$ Carlos Alberto Agnolin ${ }^{\mathrm{I} *}$ Carla Lieda Cezimbra Parra ${ }^{\mathrm{II}}$ \\ Fernanda Silveira Flores Vogel ${ }^{\mathrm{III}}$ Neila Silvia Pereira dos Santos Richards ${ }^{\mathrm{IV}}$ \\ Luiz Gustavo de Pellegrini ${ }^{\text {V }}$ Augusto Webe $^{\text {VI }}$ Felipe Pivoto $^{\text {VI }}$ Luciana Araujo $^{\text {VI }}$
}

\section{RESUMO}

\begin{abstract}
Esta pesquisa foi conduzida com o objetivo de avaliar o efeito in vitro $e$ in vivo do óleo de eucalipto (Corymbia citriodora) sobre o carrapato bovino (Rhipicephalus (Boophilus) microplus). Na experimentação in vitro, foi utilizado o grupo controle negativo e oito concentrações de óleo de eucalipto $(0,5 ; 1 ; 2 ; 5 ; 10 ; 20 ; 50 ; 100 \%)$, em fêmeas ingurgitadas de carrapato. A eficácia de controle foi de 0; 30,5; 75,5; 91; 100; 100; 100; 100 e 100\%, respectivamente. Para a experimentação in vivo, foram constituídos três grupos (controle negativo; óleo de eucalipto a 3,5\% - nível estimado mediante análise de regressão, correspondendo a $95 \%$ de eficácia de controle do carrapato da pesquisa in vitro e amitraz a 0,025\%), com dezoito vacas da raça Holandesa. Antes (média dos dias -3, -2,-1) e após a aplicação do produto (1, 2, 3, 5, 7, 10, 14, 21dias), foram contadas fêmeas ingurgitadas de carrapato. A eficácia de controle foi de 0; 96,4 e 69\%, respectivamente, 21 dias após o tratamento. Na $1^{\underline{a}}$ e na $2^{\underline{a}}$ ordenha após a aplicação dos tratamentos, foram avaliadas variáveis fisiológicas e coletadas amostras de leite para avaliar as propriedades organolépticas no leite e no iogurte (controle negativo $x$ tratamento fitoterápico). $O$ teste de aceitação sensorial do leite e das variáveis fisiológicas avaliadas foram similares entre os tratamentos.
\end{abstract}

Palavras-chave: acaricida, fitoterápico, propriedades organolépticas do leite, variáveis fisiológicas.

\section{ABSTRACT}

This research was aimed at evaluating in vitro and in vivo effects of eucalyptus (Corymbia citriodora) oil on cattle ticks (Rhipicephalus (Boophilus) microplus). Negative control group and eight concentrations of eucalyptus oil $(0.5 ; 1 ; 2 ; 5$; $10 ; 20 ; 50 ; 100 \%)$, were used on in vitro trials with engorged female ticks. The efficacy of control ticks was $0 ; 30.5$; 75.5; 91; $100 ; 100 ; 100 ; 100$ and $100 \%$, respectively. At the in vivo trial eighteen Holstein cows were allocated to three groups (negative control, eucalyptus oil at 3.5\% - level estimated by regression analysis, accounting for 95\% efficacy of control ticks on in vitro trial and amitraz at $0.025 \%)$. Engorged female ticks were counted before (mean of days -3, -2, -1) and after treatment (1, 2, 3, 5, 7, 10, 14, 21 days). The efficacy control tick was 0; 96.4 and $69 \%$, respectively, at 21 days after treatment. On the $1^{\text {st }}$ and $2^{\text {nd }}$ milked after treatments, physiologic variables were evaluate and milk samples were collected to evaluate organoleptic properties in milk and yoghurt (negative control $x$ phytotherapic treatment). Similar results were found with sensorial acceptance test of milk and physiologic variables.

Key words: acaricide, milk organoleptic properties, phytotherapic, physiologic variables.

\section{INTRODUÇÃO}

O Brasil possui um dos maiores rebanhos de bovinos do mundo, estimado em 173,2 milhões de cabeças (ANUALPEC, 2009). Dentre os parasitas que afetam os bovinos, o carrapato (Rhipicephalus

'Departamento de Zootecnia, Universidade Federal de Santa Maria (UFSM), Santa Maria, RS, Brasil.

"Programa de Pós-graduação em Zootecnia, UFSM, RS, Brasil. E-mail: caiozoot2002@yahoo.com.br. *Autor para correspondência.

IIIDepartamento de Medicina Veterinária Preventiva, UFSM, Santa Maria, RS, Brasil.

${ }^{\text {IV }}$ Departamento de Tecnologia e Ciência dos Alimentos, UFSM, Santa Maria, RS, Brasil.

vPrograma de Pós-graduação Tecnologia e Ciência dos Alimentos, UFSM, Santa Maria, RS, Brasil.

${ }^{\mathrm{v}}$ Curso de Medicina Veterinária, UFSM, Santa Maria, RS, Brasil. 
(Boophilus) microplus) é responsável por grandes perdas econômicas, em diferentes regiões do mundo (JONSSON \& PIPER, 2007). Os custos envolvidos com o controle e perdas causadas pelo carrapato, em rebanhos criados no Brasil, podem chegar a dois bilhões de dólares por ano (GRISI et al.,2002). Para o gado leiteiro, o carrapato causa diminuição na produção de leite e no ganho de peso e há possibilidade de transmissão dos agentes do complexo tristeza parasitária bovina (PATARROYO et al., 2002).

O principal método de controle envolve o uso de acaricidas sintéticos. Essa forma de controle tem causado muitos casos de intoxicações de operadores, aumento da mortalidade de animais domésticos e silvestres, contaminação dos solos, das águas e dos alimentos, afetando, direta e indiretamente a saúde das comunidades envolvidas na produção de alimentos (ROEL, 2001). Agrega-se também, a seleção de populações resistentes de $\boldsymbol{R}$. (B.) microplus em diferentes partes do mundo, tornando vários agentes químicos ineficazes (FAO, 2004). A necessidade de métodos mais seguros, menos agressivos ao homem e ao meio ambiente, tem estimulado a busca de novos acaricidas a partir de extratos vegetais, já que estes podem propiciar um desenvolvimento bem mais lento da resistência, em função de serem constituídos por vários componentes, e a redução do problema de resíduos, por serem substâncias biodegradáveis (ROEL, 2001).

Uma das plantas pesquisadas para o controle do carrapato é o eucalipto. Dentre as espécies comercias, o Corymbia citriodora é uma das mais utilizadas para a produção de óleos essencias (VITTI \& BRITO, 2003). O uso desse óleo com ação de repelência ou inseticida é descrito por alguns autores (CHAGAS et al., 2002; CLEMENTEetal., 2007; 2010), porém todos esses estudos foram realizados in vitro. Há, no entanto, poucas pesquisas associando experimentações feitas em laboratório e in vivo no controle do carrapato, bem como de possíveis efeitos do uso do produto sobre os animais e de produtos como o leite. Assim, o objetivo do trabalho foi avaliar a eficácia do óleo de eucalipto (C. citriodora) como carrapaticida em bovinos leiteiros, valendo-se de experimentações in vitro e in vivo, e verificando possíveis efeitos do produto em variáveis fisiológicas dos animais e sobre as propriedades organolépticas do leite.

\section{MATERIAL E MÉTODOS}

O eucalipto utilizado (C. citriodora) foi cultivado na mesorregião Noroeste do Rio Grande do
Sul. O óleo foi extraído da parte aérea de plantas (folha e ramos), na usina de extração de óleos essenciais por arraste a vapor do Pólo Oleoquímico de Três Passos, pertencente à Universidade do Noroeste do Estado do Rio Grande do Sul (UNIJUÍ), tendo apresentado rendimento de 1,6\%. A análise de cromatografia em fase gasosa do óleo foi realizada no Departamento de Química da Universidade Federal de Santa Maria (UFSM), apresentando, como componente majoritário, o citronelal (70,4\%). A participação do isopulegol e do citronelol foi de 16,3 e $5,5 \%$, respectivamente. Outros compostos de um total de nove perfizeram 7,8\%.

Para a experimentação in vitro, foram coletadas fêmeas ingurgitadas, com comprimento superior a $4,5 \mathrm{~mm}$, retiradas de animais da raça Holandesa, naturalmente infestados, pertencentes ao Laboratório de Bovinocultura de Leite do Departamento de Zootecnia da Universidade Federal de Santa Maria.

Os tratamentos foram constituídos pelo grupo controle e por oito diferentes concentrações do óleo de eucalipto $(0,5 ; 1,0 ; 2,0 ; 5,0 ; 10,0 ; 20,0 ; 50,0 \mathrm{e}$ $100,0 \%$, correspondendo a $5,10,20,50,100,200,500 \mathrm{~mL}$ $\mathrm{L}^{-1}$ e óleo puro, respectivamente. Para o grupo controle (testemunha, sem óleo) e para a complementação das demais soluções (até o nível de 50\%), usou-se água destilada. As fêmeas ingurgitadas foram pesadas e colocadas em grupos de 10 em cada placa de Petri, sendo usadas três repetições por tratamento, submetidas ao Teste de imersão de fêmeas ingurgitadas (DRUMMOND et al., 1973), realizado no Laboratório de Doenças Parasitárias da UFSM. O delineamento experimental utilizado foi o inteiramente casualizado, com nove tratamentos.

$\mathrm{O}$ experimento in vivo foi realizado no Laboratório de Bovinocultura de Leite (DZ, UFSM). Foram constituídos três tratamentos: amitraz a $0,025 \%$ (grupo controle positivo), óleo de eucalipto a 3,5\% e testemunha (grupo controle negativo). A opção pelo amitraz deveu-se à eficácia in vitro de $98,2 \%$ no controle da cepa utilizada no presente experimento. Para a concentração com óleo de eucalipto, o nível utilizado $3,5 \%$, teve como base os resultados da experimentação in vitro, sendo submetidos à análise de regressão polinomial, estimando-se um valor de $95 \%$ de eficácia.

Nas avaliações, foram utilizadas 18 vacas em lactação da raça Holandesa, infestadas naturalmente com carrapato. Os animais tinham cerca de $518 \mathrm{~kg}$ de peso vivo e produção média de $19,7 \mathrm{~kg}$ de leite vaca-1 
$\mathrm{dia}^{-1}$, sendo submetidos diariamente a duas ordenhas e manejados em conjunto em pastagens perenes de ciclo estival. A complementação alimentar foi feita com concentrado (18\% PB) à razão de $4,5 \mathrm{~kg} \mathrm{vaca}^{-1} \mathrm{dia}^{-1}$, dividida entre as ordenhas da manhã e da tarde. $\mathrm{O}$ critério para utilização de cada animal foi a infestação de carrapatos, sendo usadas vacas que apresentavam no mínimo dez teleóginas (média de três dias consecutivos). As soluções foram preparadas e aplicadas após a ordenha da tarde, utilizando-se de pulverizador costal. A quantidade de calda usada foi de 4 litros vaca-1 .

Nas avaliações, foram efetuadas contagens de carrapato, considerando-se os ínstares com tamanho superior a 4,5mm de comprimento, na metade do corpo do animal, multiplicando-se o valor por dois para a obtenção da infestação total (WHARTON et al., 1970). As contagens foram feitas no $1^{\circ}, 2^{\circ}, 3^{\circ}, 5^{\circ}, 7 \circ, 10^{\circ}, 14^{\circ} \mathrm{e}$ $21^{\circ}$ dia após a aplicação dos produtos. Para calcular a eficácia do produto, foi utilizada a seguinte fórmula: Eficácia $=[$ (№ de teleóginas de pré-tratamento - № de teleóginas do dia de pós-tratamento) *100 / № de teleóginas de pré-tratamento]. O delineamento experimental utilizado foi o inteiramente casualizado, com três tratamentos e seis repetições (vacas), sendo que, para a variável número de teleóginas, os dados foram analisados após a transformação logarítmica de base 10 .

Para a análise das características sensoriais do leite e iogurte e a avaliação das variáveis fisiológicas, conduziu-se outra experimentação, mantendo-se os mesmos tratamentos. Para análise das características sensoriais do leite e iogurte, foram retiradas amostras de leite antes da aplicação da solução com óleo de eucalipto e na 1a e 2a ordenhas após a aplicação do banho, sendo avaliadas no Departamento de Ciência e Tecnologia dos Alimentos (UFSM). Para análise da cor, odor, sabor e aparência geral, utilizou-se uma escala hedônica não estruturada de sete pontos: 1 - desgostei muito; 2 - desgostei regularmente; 3 - desgostei; 4 indiferente, nem gostei, nem desgostei; 5 - gostei; 6 gostei regularmente; 7 - gostei muito. Para o teste de sabor em relação ao padrão, utilizando leite comercial, foi realizado um teste de comparação múltipla (para o leite e iogurte), com escala de sete pontos: 1 extremamente pior que o controle; 2 - muito pior que o controle; 3 - regularmente pior que o controle; 4 nenhuma diferença do controle; 5 - regularmente melhor que o controle; 6 - muito melhor que o controle; 7 extremamente melhor que o controle (DUTCOSKY,
2007). Os testes foram realizados por vinte provadores, sendo que cada um recebeu uma ficha para a avaliação dos parâmetros descritos.

As amostras de leite foram submetidas à análise de gordura, lactose, proteína, sólidos não gordurosos e acidez, realizadas em triplicata, segundo os métodos analíticos oficiais físico-químicos para controle de leite e produtos lácteos definidos pelo Ministério da Agricultura e Abastecimento (BRASIL, 2006).

As variáveis fisiológicas foram aferidas antes e às 3, 6 e 24 horas após a aplicação dos tratamentos. As frequências cardíaca e respiratória foram verificadas mediante auscultação com estetoscópio. Para aferir as temperaturas de globo ocular e da superfície da pele utilizou-se equipamento com infravermelho (TI 890 Instron com resolução de 50x).

O delineamento experimental foi $\mathrm{o}$ inteiramente casualizado, com quatro repetições (vacas), sendo os tratamentos constituídos pelos grupos controle negativo e da solução com 3,5\% de óleo de eucalipto. Para ambos os experimentos (in vitro e in vivo), os dados foram submetidos à análise de variância e as médias comparadas pelo teste de Tukey ao nível de 5\% de probabilidade do erro. Foi utilizado o modelo matemático: $\mathrm{Y}_{\mathrm{ij}}=\mathrm{m}+\mathrm{T}_{\mathrm{i}}+\mathrm{e}_{\mathrm{ij}}$, em que, $\mathrm{Y}_{\mathrm{ij}}$ representa a variável dependente; $\mathrm{i}=\mathrm{o}$ índice de tratamentos; $\mathrm{j}=$ o índice de repetições; m é a média de todas as observações; $\mathrm{T}_{\mathrm{i}}$ corresponde ao efeito dos tratamentos; $\mathrm{e}_{\mathrm{ij}}$ é o efeito do erro. Os dados foram analisados com auxílio do programa estatístico SAS (1997).

\section{RESULTADOS E DISCUSSÃO}

Com relação à experimentação in vitro (Tabela 1$)$, observa-se que houve efeito $(\mathrm{P}<0,05)$ a partir de $2 \%$ de óleo de eucalipto sobre a eclodibilidade dos ovos. Não houve eclodibilidade com níveis de concentração a partir de $5 \%$ de óleo. Os dados submetidos à análise de regressão ( $Y=92,224+4,802 \mathrm{x}-$ $4,651 \mathrm{x}^{2} ; \mathrm{R}^{2}=0,99 ; \mathrm{P}=0,0012$ ) demonstram efeito inicial descendente para eclodibilidade, à medida que se aumenta a concentração do óleo de eucalipto nas soluções.

Para eficácia, houve efeito $(\mathrm{P}<0,05)$ a partir da solução com nível de $0,5 \%$ de óleo de eucalipto. A partir de 5\% de óleo de eucalipto, a eficácia foi de $100 \%$. Os dados submetidos à análise de regressão $\left(\mathrm{Y}=11,875+53,426 \mathrm{x}-8,479 \mathrm{x}^{2} ; \mathrm{R}^{2}=0,88 ; \mathrm{P}=0,0042\right)$ demonstram efeito quadrático com início ascendente. 
Tabela 1 - Médias porcentuais de eclodibilidade e da eficácia das soluções constituídas por diferentes concentrações de óleo de eucalipto (Corymbia citriodora Hooker) em teleóginas de Rhipicephalus (Boophilus) microplus pelo Teste de imersão de teleóginas. Santa Maria, RS, 2011.

\begin{tabular}{lcc}
\hline $\begin{array}{c}\text { Tratamentos } \\
(\%)\end{array}$ & $\begin{array}{c}\text { Eclodibilidade } \\
(\%)\end{array}$ & $\begin{array}{c}\text { Eficácia do produto } \\
(\%)\end{array}$ \\
\hline 0,0 (controle) & $98,5^{\mathrm{a}}$ & $0,0^{\mathrm{d}}$ \\
0,5 & $92,5^{\mathrm{ab}}$ & $30,5^{\mathrm{c}}$ \\
1,0 & $84,0^{\mathrm{a}}$ & $75,5^{\mathrm{b}}$ \\
2,0 & $82,5^{\mathrm{b}}$ & $91,0^{\mathrm{a}}$ \\
5,0 & $0,0^{\mathrm{c}}$ & $100,0^{\mathrm{a}}$ \\
10,0 & $0,0^{\mathrm{c}}$ & $100,0^{\mathrm{a}}$ \\
20,0 & $0,0^{\mathrm{c}}$ & $100,0^{\mathrm{a}}$ \\
50,0 & $0,0^{\mathrm{c}}$ & $100,0^{\mathrm{a}}$ \\
100,0 & $0,0^{\mathrm{c}}$ & $100,0^{\mathrm{a}}$ \\
CV $(\%)$ & 6,40 & 4,28 \\
\hline
\end{tabular}

Médias com letras distintas, na coluna, indicam diferença significativa $(\mathrm{P}<0,05)$ pelo teste de Tukey; Óleo de eucalipto oriundo do Laboratório de Óleos Essenciais (UNIJUÍ - Ijuí, RS), do Pólo Oleoquímico de Três Passos, RS. CV= Coeficiente de variação.

Em pesquisas conduzidas com a mesma espécie de eucalipto, mas utilizando o etanol como solvente, foram observados resultados um pouco inferiores para os níveis de 5, 10 e 20\% (CHAGAS et al., 2002).

Em pesquisa realizada in vitro, na qual foram utilizados óleos de eucalipto (C. citriodora) e de citronela (Cymbopogon nardus) em soluções, utilizando água como solvente, contendo 50; 25; $12,5 \mathrm{e}$ 6,25\% de óleo, foi observada ação acaricida de 93,98; 80,$23 ; 72,23$ e 49,66\% para o eucalipto e 77,$56 ; 65,53$; 31,23 e $30 \%$ para a citronela, no controle do $\boldsymbol{R}$. (B.) microplus (CLEMENTE et al., 2007). Para os autores, o resultado superior do eucalipto já era esperado em virtude do maior teor de citronelal, substância com ação inseticida comprovada. Também CHAGAS et al. (2002) atribuíram a ação acaricida do óleo de citronela ao princípio ativo citronelal. Em outra pesquisa, utilizando óleo de eucalipto ( $\boldsymbol{C}$. cidriodora) na concentração de $6,25 \%$, em solução aquosa, observou-se mortalidade larval de 10,8 e 20,1\% para as espécies Amblyomma cajennense e Anocentor nitens, respectivamente (CLEMENTE et al., 2010).

Para eficácia no controle de teleóginas (Tabela 2), observa-se que a ação do produto químico foi mais rápida, implicando controle superior a $90 \%$ a partir do $2^{\circ}$ dia pós-banho, sendo superior $(\mathrm{P}<0,05) \mathrm{em}$ relação à solução de óleo de eucalipto, até o 7 ํㅓㅁ pósbanho; entre o $10^{\circ}$ e o $14^{\circ}$ dia os valores de controle são similares. Na avaliação feita no $21^{\circ}$ dia, observa-se que a eficácia do óleo de eucalipto manteve-se acima de $95 \%$, sendo superior $(\mathrm{P}<0,05)$ ao grupo tratado com amitraz. Esse resultado demonstra que o óleo de eucalipto age sobre as diferentes fases de vida parasitária do carrapato. Essa assertiva também é confirmada a partir da comparação com o grupo controle, no qual verificou-se aumento de teleóginas. No grupo tratado com óleo de eucalipto, verificou-se declínio constante até o final da avaliação ( $21^{\circ}$ dia). A solução constituída pelo óleo de eucalipto a 3,5\% apresenta desempenho semelhante ao produto químico a partir do $10^{\circ}$ dia, e superior no $21^{\circ}$ dia pós-banho para o controle da infestação de carrapatos. Os resultados entre a eficácia obtida in vitro, de 95\% (para o nível estimado de 3,5\% de óleo de eucalipto, mediante análise de regressão), foram superiores ao valor verificado in vivo, na média dos dias pós-banho, porém os valores do $14^{\circ}$ e $21^{\circ}$ dia são superiores a $90 \%$, o que comprova o efeito do produto nas formas imaturas do carrapato. Deve-se destacar, no entanto, que o citronelal é um dos componentes do óleo que apresenta elevada volatilidade (ZHU et al., 2001). Embora esse efeito, o aumento na atividade de repelência de óleos essenciais é altamente dependente da composição do produto, assim, formulações à base de cremes, misturas de polímeros, ou microcápsulas de liberação controlada, proporcionam um aumento da duração da repelência (NENTWIG, 2003), podendo, provavelmente, contribuir para melhor ação do produto aplicado in vivo.

Quanto à análise sensorial do leite (Tabela 3), não foram observadas diferenças entre tratamentos. Os valores obtidos, em torno de quatro, são considerados adequados para o leite pasteurizado. $\mathrm{Na}$ avaliação do iogurte, foram observadas diferenças $(\mathrm{P}<0,05)$ para os parâmetros sabor e aparência geral, na $1^{\mathrm{a}}$ ordenha pósbanho, com menor valor nas vacas tratadas com óleo de eucalipto, embora os valores obtidos tenham ficado entre os padrões indiferente e gostei, considerados adequados nessa escala de avaliação.

Para as variáveis fisiológicas frequência cardíaca, frequência respiratória, temperatura do globo ocular e temperatura da pele, não foram observadas diferenças entre as vacas do grupo controle e aquelas 
Tabela 2 - Uso de solução aquosa contendo óleo de eucalipto (Corymbia citriodora Hooker) e do amitraz no controle do carrapato Rhipicephalus (Boophilus) microplus em bovinos da raça Holandesa. Santa Maria, RS, 2011.

\begin{tabular}{|c|c|c|c|c|}
\hline \multirow{2}{*}{ Avaliações } & & ero de teleóg & & \multirow{2}{*}{$\mathrm{CV}(\%)$} \\
\hline & Controle $^{2}$ & Eucalipto $^{3}$ & Amitraz $^{4}$ & \\
\hline Pré-tratamento & $30,4^{\mathrm{b}}$ & $60,4^{\mathrm{a}}$ & $47,6^{\mathrm{ab}}$ & 10,6 \\
\hline $1^{\varrho} \mathrm{dia}$ & $42,0^{\mathrm{a}}$ & $49,6^{\mathrm{a}}$ & $16,6^{\mathrm{b}}$ & 12,9 \\
\hline $2^{\mathrm{o}} \mathrm{dia}$ & $43,6^{\mathrm{a}}$ & $27,4^{\mathrm{b}}$ & $3,2^{\mathrm{c}}$ & 18,5 \\
\hline $3^{\circ}$ dia & $50,0^{\mathrm{a}}$ & $23,2^{\mathrm{b}}$ & $0,8^{\mathrm{c}}$ & 10,3 \\
\hline $5^{\circ}$ dia & $39,6^{\mathrm{a}}$ & $15,0^{\mathrm{b}}$ & $2,2^{\mathrm{b}}$ & 26,4 \\
\hline $7^{0} \mathrm{dia}$ & $37,6^{\mathrm{a}}$ & $13,2^{\mathrm{b}}$ & $2,0^{\mathrm{c}}$ & 21,9 \\
\hline $10^{\circ} \mathrm{dia}$ & $33,4^{\mathrm{a}}$ & $7,2^{\mathrm{b}}$ & $4,8^{\mathrm{b}}$ & 37,7 \\
\hline $14^{\circ} \mathrm{dia}$ & $32,0^{\mathrm{a}}$ & $5,8^{\mathrm{b}}$ & $1,2^{\mathrm{b}}$ & 38,8 \\
\hline $21^{\circ} \stackrel{\mathrm{dia}}{ }$ & $35,4^{\mathrm{a}}$ & $2,0^{\mathrm{b}}$ & $14,2^{\mathrm{ab}}$ & 29,6 \\
\hline Média Pós-tratamento & $39,2^{\mathrm{a}}$ & $17,9^{\mathrm{b}}$ & $5,6^{\mathrm{c}}$ & 27,4 \\
\hline Pré-tratamento & 0,0 & 0,0 & 0,0 & 0,0 \\
\hline $1^{\underline{0}} \mathrm{dia}$ & $0,0^{\mathrm{c}}$ & $18,0^{\mathrm{b}}$ & $64,4^{\mathrm{a}}$ & 36,2 \\
\hline $2^{\underline{o}}$ dia & $0,0^{\mathrm{c}}$ & $52,2^{\mathrm{b}}$ & $93,6^{\mathrm{a}}$ & 31,1 \\
\hline $2^{\underline{o}}$ dia & $0,0^{\mathrm{c}}$ & $52,2^{\mathrm{b}}$ & $93,6^{\mathrm{a}}$ & 31,1 \\
\hline $3^{\mathrm{o}} \mathrm{dia}$ & $0,0^{\mathrm{c}}$ & $58,0^{\mathrm{b}}$ & $98,8^{\mathrm{a}}$ & 32,2 \\
\hline $5^{\frac{\mathrm{o}}{\mathrm{dia}}}$ & $0,0^{\mathrm{c}}$ & $73,0^{\mathrm{b}}$ & $96,6^{\mathrm{a}}$ & 21,0 \\
\hline $7^{\underline{0}}$ dia & $0,0^{\mathrm{c}}$ & $77,2^{\mathrm{b}}$ & $96,6^{\mathrm{a}}$ & 10,1 \\
\hline $10^{\underline{o}} \mathrm{dia}$ & $0,0^{\mathrm{b}}$ & $88,4^{\mathrm{a}}$ & $91,4^{\mathrm{a}}$ & 7,5 \\
\hline $14^{\mathrm{o}} \mathrm{dia}$ & $0,0^{\mathrm{b}}$ & $90,8^{\mathrm{a}}$ & $97,2^{\mathrm{a}}$ & 6,3 \\
\hline $21^{\circ} \mathrm{dia}$ & $0,0^{\mathrm{c}}$ & $96,4^{\mathrm{a}}$ & $69,0^{\mathrm{b}}$ & 16,9 \\
\hline Média Pós-tratamento & $0,0^{\mathrm{c}}$ & $69,2^{\mathrm{b}}$ & $88,4^{\mathrm{a}}$ & 25,5 \\
\hline
\end{tabular}

Médias com letras distintas, na linha, indicam diferença significativa $(\mathrm{P}<0,05)$ pelo teste de Tukey; ${ }^{1}$ dados de número de teleóginas analisados após a transformação logarítmica de base $10 ;{ }^{2}$ Controle $=$ grupo controle negativo; ${ }^{3}$ Eucalipto $=$ solução aquosa contendo $3,5 \%$ de óleo de eucalipto; ${ }^{4}$ Amitraz $=0,025 \%$ de amitraz, grupo controle positivo.

banhadas com a solução constituída por óleo de eucalipto. Os valores levantados na avaliação inicial, antecedendo a aplicação do tratamento, às $9 \mathrm{~h}$, demonstram que os animais apresentavam variáveis fisiológicas normais (SMITH, 1994). Observou-se, no entanto, que nos dois grupos houve elevação dos valores da frequência cardíaca (de 68,1 para 77,3 batimentos minuto $^{-1}$ ) e respiratória (de 31,2 para 49,5 movimentos minuto $^{-1}$ ) entre as 09 e as $15 \mathrm{~h}$, respectivamente, comprovando que os animais tiveram um período de estresse térmico durante o dia.

Os resultados podem ser importantes como estratégias de controle do carrapato em diferentes sistemas de produção, uma vez que o produto fitoterápico demonstrou ter ação sobre a cepa de carrapato testada. Constata-se, no entanto, a necessidade de se realizar novos estudos para otimizar a utilização do óleo de eucalipto, mediante novas formulações, especialmente na avaliação com emulsionantes, na forma de aplicação e no intervalo de utilização do produto constituído.

\section{CONCLUSÃO}

As soluções contendo níveis crescentes de óleo de eucalipto avaliados in vitro apresentam efeito quadrático ascendente no controle do carrapato. Entre as avaliações in vitro e in vivo, houve similaridade no controle do carrapato. Entre os grupos de animais não tratados e os que foram banhados com solução contendo óleo de eucalipto, houve similaridade tanto nas propriedades organolépticas do leite quanto nas variáveis fisiológicas dos animais. 
Tabela 3 - Dados médios da análise sensorial do leite cru e do iogurte após a aplicação de solução contendo óleo de eucalipto (Corymbia citriodora Hooker) no controle do carrapato Rhipicephalus (Boophilus) microplus em vacas da raça Holandesa. Santa Maria, RS, 2011.

\begin{tabular}{|c|c|c|c|c|c|c|c|}
\hline \multirow[b]{2}{*}{ Parâmetros } & \multirow[b]{2}{*}{ Grupos } & \multicolumn{3}{|c|}{------Análise sensorial do leite-------- } & \multicolumn{3}{|c|}{-------Análise sensorial do iogurte-------- } \\
\hline & & $\begin{array}{l}8 \text { horas } \\
\text { pós-banho }\end{array}$ & $\begin{array}{l}24 \text { horas } \\
\text { pós-banho }\end{array}$ & $\mathrm{CV} \%$ & $\begin{array}{l}8 \text { horas } \\
\text { pós-banho }\end{array}$ & $\begin{array}{l}24 \text { horas } \\
\text { pós-banho }\end{array}$ & $\mathrm{CV} \%$ \\
\hline \multirow{2}{*}{ Cor } & Controle $^{1}$ & 4,4 & 4,8 & \multirow{2}{*}{21,7} & 4,9 & 4,7 & \multirow{2}{*}{17,6} \\
\hline & Eucalipto $^{2}$ & 4,9 & 4,5 & & 4,9 & 4,8 & \\
\hline \multirow{2}{*}{ Odor } & Controle & 3,9 & 4,3 & \multirow{2}{*}{24,3} & 5,0 & 4,5 & \multirow{2}{*}{19,8} \\
\hline & Eucalipto & 4,5 & 4,7 & & 4,7 & 4,9 & \\
\hline \multirow{2}{*}{ Sabor } & Controle & 3,5 & 4,2 & \multirow{2}{*}{35,6} & $5,4^{\mathrm{a}}$ & 4,7 & \multirow{2}{*}{28,4} \\
\hline & Eucalipto & 3,9 & 3,9 & & $4,4^{\mathrm{b}}$ & 4,8 & \\
\hline \multirow{2}{*}{ Aparência geral } & Controle & 4,4 & 4,6 & \multirow{2}{*}{24,7} & $5,3^{\mathrm{a}}$ & 4,4 & \multirow{2}{*}{22,1} \\
\hline & Eucalipto & 5,0 & 4,7 & & $4,7^{\mathrm{b}}$ & 4,7 & \\
\hline \multirow{2}{*}{ Sabor/padrão } & Controle & 4,3 & 5,5 & \multirow{2}{*}{39,0} & 6,1 & 6,4 & \multirow{2}{*}{28,2} \\
\hline & Eucalipto & 4,8 & 4,8 & & 6,0 & 6,6 & \\
\hline
\end{tabular}

Propriedades físico-químicas do leite: gordura $(\%)=2,5$ e 3,4; lactose $(\%)=4,0$ e 4,2; proteína $(\%)=3,2$ e 3,3; sólidos não gordurosos $(\%)=$ 9,4 e 9,8; acidez ( ${ }^{\circ}$ Dornic) $=15,4$ e 15,3 para o grupo controle e óleo de eucalipto, respectivamente. Médias com letras distintas, na coluna, indicam diferença significativa $(\mathrm{P}<0,05)$ pelo teste $\mathrm{F} ;{ }^{1}$ Controle $=$ grupo controle negativo; ${ }^{2}$ Eucalipto $=$ solução aquosa contendo $3,5 \%$ de óleo de eucalipto.

\section{COMITÊ DE ÉTICA E BIOSSEGURANÇA}

Protocolo 23081016073/2011-27. Parecer 113/2011.

\section{REFERÊNCIAS}

ANUAlPEC. Anuário da Pecuária Brasileira. São Paulo: Angra FNP Pesquisas, 2009. 360p.

BRASIL. Ministério da Agricultura e do Abastecimento. Instrução Normativa 68 de 12 de dezembro de 2006. Métodos analíticos oficiais físico-químicos, para controle de leite e produtos lácteos. Brasília- DF, 2006.

CHAGAS, A.C.S. et al. Efeito acaricida de óleos essenciais e concentrados emulsionáveis de Eucalyptus spp em Boophilus microplus. Brazilian Journal of Veterinary Research and Animal Science, v.39, n.5, p.247-253, 2002. Disponível em: $<\mathrm{http} / / / \mathrm{www}$. scielo.br/scielo.php?script=sci_arttext\&pid=S1413$95962002000500006 \& \operatorname{lng}=$ en $\& n r m=i s o \& t \operatorname{lng}=\mathrm{pt}>$. Acesso em: 05 mar. 2012. doi: 10.1590/S1413-95962002000500006.

CLEMENTE, M.A. et al. Avaliação do potencial de plantas medicinais no controle de Boophilus microplus (Acari: Ixodidae). Revista Brasileira de Biociências, v.1, s.2, p.516-518, 2007. Disponível em: <http://www6.ufrgs.br/seerbio/ojs/index.php/rbb/ article/view/460/404>. Acesso em: 06 mar. 2012.

CLEMENTE, M.A. et al. Acaricidal activity of the essential oils from Eucalyptus citriodora and Cymbopogon nardus on larvae of Amblyomma cajennense (Acari: Ixodidae) and Anocentor nitens (Acari: Ixodidae). Parasitology Research, v.107, n.4, p.987-992, 2010. Disponível em: <http:// www.springerlink.com/content/105086rq0t14j474/fulltext.pdf>. Acesso em: 06 mar.2012. doi: 10.1007/s00436-010-1965-0.

DRUMMOND, R.O. et al. Boophilus annulatus and Boophilus microplus: Laboratory test of insecticides. Journal of Economic Entomology, v.66, n.1, p.130-133, 1973.

DUTCOSKY, S.D. Análise sensorial de alimentos. 2.ed. Curitiba: Champagnat, 2007. 239p.

FAO (FOOD AND AGRICULTURE ORGANIZATION). Guidelines resistance management and integrated parasite control in ruminants. Roma: Food and Agriculture Organization of the United Nations, 2004. 77p.

GRISI, L. et al. Impacto econômico das principais ectoparasitoses em bovinos no Brasil. A Hora Veterinária, v.21, n.125, p.8-10, 2002.

JONSSON, N.N.; PIPER, E.K. Integrated control programs for ticks on cattle. Queensland: The University of Queensland, 2007. 163p.

MARTINEZ M.L. et al. Association of BoLA-DRB3.2 alleles with tick (Boophilus microplus) resistance in cattle. Genetics and Molecular Research, v.5, n.3, p.513-524, 2006. Disponível em: <http://www.funpecrp.com.br/gmr/year2006/ vol3-5/gmr0211_full_text.htm>. Acesso em: 07 mar. 2012.

NENTWIG, G. Use of repellents as prophylactic agents. Parasitology research, v.90, n.1, p.40-48, 2003. Disponível em: <http://www.springerlink.com/content/15x2g004jgw50vd5/ 
fulltext.pdf $>$. Acesso em: 06 mar. 2012. doi: 10.1007/s00436002-0755-8.

PATARROYO, J.H. et al. Immunization of cattle with synthetic peptides derived from the Boophilus microplus gut protein (Bm86). Veterinary Immunology and Immunopathology, v.88, n.3/4, p.163-172, 2002. Disponível em: <http://www.sciencedirect.com/ science/article/pii/S016524270200154X>. Acesso em: 06 mar. 2012.

ROEL, A.R. Utilização de plantas com propriedades inseticidas: uma contribuição para o desenvolvimento rural sustentável. Revista Internacional de Desenvolvimento Local, v.1, n.2, p.43-50, 2001. Disponível em: <http://www.sumarios.org/sites/ default/files/pdfs/36212_4552.PDF>. Acesso em: 08 mar. 2012.

SAS (STATISTICAL ANALISYS SYSTEM). User's guide, Stat. 2.ed. Cary, 1997. 456p.
SMITH, B.P. Tratado de medicina interna de grandes animais. 2.ed. São Paulo: Manole, 1994. 1738p.

VITTI, A.M.S; BRITO, J.O. Óleos essenciais de eucalipto. Piracicaba: ESALQ, 2003. 26p. (Boletin Técnico, 17).

WHARTON, R.H. et al. Assessment of the efficiency of acaricides and their mode of aplication against the cattle tick Boophilus microplus. Australian Journal of Agricultural Research, v.21, n.5, p.985-1006, 1970.

ZHU, B.C.R. et al. Evaluation of vetiver oil and seven insectactive essential oils against the formosan subterranean termite. Journal of Chemical Ecology, v.27, n.8, p.1617-1625, 2001. Disponível em: <http://www.springerlink.com/content/ w281570500831452/fulltext.pdf>. Acesso em: 08 mar. 2012. doi: $10.1023 / \mathrm{A}: 1010410325174$. 